\title{
Nordic Seas total dissolved inorganic carbon data in CARINA
}

\author{
A. Olsen \\ Bjerknes Centre for Climate Research, Uni Research, Allégaten 55, 5007 Bergen, Norway \\ Department of Chemistry, University of Gothenburg, 41296, Göteborg, Sweden \\ Received: 1 July 2009 - Published in Earth Syst. Sci. Data Discuss.: 5 August 2009 \\ Revised: 17 November 2009 - Accepted: 18 November 2009 - Published: 25 November 2009
}

\begin{abstract}
Water column data of carbon and carbon relevant hydrographic and hydrochemical parameters from 188 previously non-publicly available cruises in the Arctic, Atlantic, and Southern Ocean have been retrieved and merged into a new database: CARINA (CARbon IN the Atlantic). The data have been subject to rigorous quality control (QC) in order to ensure highest possible quality and consistency. The data for most of the parameters included were examined in order to quantify systematic biases in the reported values, i.e. secondary quality control. Significant biases have been corrected for in the data products, i.e. the three merged files with measured, calculated and interpolated values for each of the three CARINA regions; the Arctic Mediterranean Seas (AMS), the Atlantic (ATL) and the Southern Ocean (SO). With the adjustments the CARINA database is consistent both internally as well as with GLODAP (Key et al., 2004) and is suitable for accurate assessments of, for example, oceanic carbon inventories and uptake rates and for model validation. The Arctic Mediterranean Seas includes the Arctic Ocean and the Nordic Seas, and the quality control was carried out separately in these two areas. This contribution presents an account of the quality control of the total dissolved inorganic carbon $\left(\mathrm{TCO}_{2}\right)$ data from the Nordic Seas in CARINA. Out of the 35 cruises from the Nordic Seas included in CARINA, 25 had $\mathrm{TCO}_{2}$ data. The data from 7 of these were found to be of low quality and should not be used, thus the final CARINA data product contains $\mathrm{TCO}_{2}$ data from 18 cruises from the Nordic Seas. These data appear consistent to at least $4 \mu \mathrm{mol} \mathrm{kg}^{-1}$.
\end{abstract}

\section{Data coverage and parameter measured}

Repository-Reference:

doi:10.3334/CDIAC/otg.CARINA.AMS.V1.2

Available at:

http://cdiac.ornl.gov/oceans/CARINA/Carina_inv.html

Coverage: $59.60^{\circ} \mathrm{N}-82.35^{\circ} \mathrm{N}, 35.23^{\circ} \mathrm{W}-20^{\circ} \mathrm{E}$

Location Name: Nordic Seas

Date/Time Start: 1991-8-15

Date/Time End: 2006-02-10

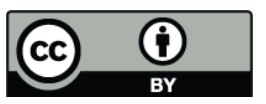

Correspondence to: A. Olsen

(are.olsen@gfi.uib.no)

Published by Copernicus Publications. 


\begin{tabular}{lllll}
\hline $\begin{array}{l}\text { Data Product } \\
\text { Parameter Name }\end{array}$ & $\begin{array}{l}\text { Data Product } \\
\text { Flag name }\end{array}$ & $\begin{array}{l}\text { Exchange File } \\
\text { Parameter Name }\end{array}$ & $\begin{array}{l}\text { Exchange File } \\
\text { Flag Name }\end{array}$ & Units \\
\hline station & & STANBR & & \\
day & & DATE $^{\mathrm{a}}$ & & \\
month & & DATE $^{\mathrm{a}}$ & & \\
year & & DATE $^{\mathrm{a}}$ & & decimal degrees \\
latitude & & LATITUDE & & decimal degrees \\
$\begin{array}{l}\text { longitude } \\
\text { cruiseno }\end{array}$ & & LONGITUDE & & \\
$\begin{array}{l}\text { depth } \\
\text { temperature }\end{array}$ & & & & meters \\
salinity & sf & CTDTMP & & ${ }^{\circ} \mathrm{C}$ \\
ctdsal & ctdsf & CALNTY & SALNTY_FLAG_W & \\
pressure & & CTDPRS & CTDSAL_FLAG_W & \\
tco2 & tco2f & TCARBN & TCARBN_FLAG_W & $\mu$ decibars $\mathrm{kg}^{-1}$ \\
\hline
\end{tabular}

${ }^{\text {a }}$ DATE contains year, month and day as YYYYMMDD.

For a complete list of all parameters available in CARINA see Key et al. (2009). Note the different names for the parameters in the Exchange files (the individual cruise files) and the merged data product.

\section{Introduction}

CARINA (CARbon In the Atlantic) is a database of carbon and carbon-relevant data from hydrographic cruises in the Arctic, Atlantic and Southern Oceans. The project started as an essentially informal, unfunded project in Delmenhorst, Germany, in 1999 during the workshop on " $\mathrm{CO}_{2}$ in the North Atlantic", with the main goal to create a uniformly formatted database of carbon relevant variables in the ocean to be used for accurate assessments of oceanic carbon inventories and uptake rates. The collection of data and the quality control (QC) of the data have been a main focus of the CARINA project. Both primary and secondary QC of the data has been performed.

The CARINA database consists of two parts: the first part is the set of the individual cruise files where all the data reported by the measurement teams are stored. Quality flags are accompanying the data, in many cases these are the flags originally reported, in others they were assigned by R. M. Key, Princeton University. These files are in WHP (WOCE Hydrographic Program) exchange format where the first lines consist of the condensed metadata. There are essentially no calculated or interpolated values in the individual cruise files, with the exceptions of pressure calculated from depth and some bottle salinities that were taken from ctdsal. No adjustments have been applied to any of these values with the exception that all $\mathrm{pH}$ measurements were converted to the seawater $\mathrm{pH}$ scale at $25^{\circ} \mathrm{C}$ (Velo et al., 2009).

The second part of CARINA consists of three merged, quality controlled and adjusted data files; one each for the Atlantic Ocean, Arctic Mediterranean Seas and Southern Ocean regions. These files contain all the CARINA data and also include: 1) interpolated values for nutrients, oxygen and salinity if those data were missing and the interpolation could be made according to certain criteria, as described in Key et al. (2009); 2) calculated carbon parameters; e.g. if total dissolved inorganic carbon $\left(\mathrm{TCO}_{2}\right)$ and total alkalinity (TA) were measured, $\mathrm{pH}$ was calculated; and 3) instances where bottle salinity was missing or bad and were replaced with CTD salinity. Calculated or interpolated values have been given the quality flag " 0 ". In many cases there are additional parameters in the individual cruise files, which have not been included in the secondary QC, such as $\Delta^{14} \mathrm{C}, \delta^{13} \mathrm{C}$ and $\mathrm{SF}_{6}$. Many of these are included in the merged data files as well.

This report provides an overview of the $\mathrm{TCO}_{2}$ data from the Nordic Seas data in CARINA and describes the secondary QC of these data. These data are part of the Arctic Mediterranean Seas subset of CARINA (CARINA-AMS). This subset includes data from the Nordic Seas and the Arctic Ocean. Not one of the cruises of CARINA covered both the Arctic Ocean and the Nordic Seas to the extent that it could be included in the secondary quality control in both regions. In addition, the differences in data density in the two regions enforced the use of different QC methods for the data collected in them. The data from these regions were therefore analysed separately, and the data from the Arctic Ocean are described by Jutterström et al. (2009) while the other Nordic Seas data are described in Jeansson et al. (2009), Falck and Olsen (2009), Olafsson and Olsen, (2009), Olsen et al. (2009), and Olsen (2009). A more comprehensive description of the complete CARINA database can be found in Key et al. (2009), as well as in the other, more specialised, papers in this special issue. 
Table 1. CARINA cruises with $\mathrm{TCO}_{2}$ data in the Nordic Seas.

\begin{tabular}{|c|c|c|c|c|c|c|c|}
\hline $\mathrm{No}^{\mathrm{a}}$ & EXPOCODE & Country/Institute & PI & $\mathrm{CRM}^{\mathrm{b}}$ & Method & No. Samples & $\operatorname{Rec}^{\mathrm{c}}$ \\
\hline 10 & 06MT19920701d & Germany/IBM Hamburg & K. Pegler & Not known & Not known & 154 & Flag 3 \\
\hline 36 & 18HU19820228 & Canada/BiO & E. P. Jones & no & potentiometric titration & 921 & Flag 3 \\
\hline 67 & 316 N20020530 & Norway/UoB & R. G. J. Bellerby & yes & SOMMA & 1800 & $\mathrm{OK}$ \\
\hline 78 & 32L919920715 & USA/Brookhaven & D. W. R. Wallace & yes & SOMMA $^{\mathrm{e}}$ & 73 & $\mathrm{NC}$ \\
\hline 79 & 32L919930718 & USA/Brookhaven & D. W. R. Wallace & yes & SOMMA & 828 & $\mathrm{NC}$ \\
\hline 116 & 58AA19940203 & Norway/UoB & I. Skjelvan & yes & SOMMA & 84 & Flag 3 \\
\hline 117 & 58AA19940224 & Norway/UoB, Sweden/UGOT & T. Johannessen, L. G. Anderson & yes & SOMMA & 440 & $\mathrm{OK}$ \\
\hline 118 & 58AA19940826 & Norway/UoB & T. Johannessen & yes & SOMMA & 475 & $\mathrm{OK}$ \\
\hline 119 & 58AA19950217 & Norway/UoB, Sweden/UGOT & T. Johannessen, L. G. Anderson & yes & SOMMA & 407 & Flag 3 \\
\hline 120 & 58AA19961121 & Norway/UoB & T. Johannessen & yes & SOMMA & 365 & $\mathrm{OK}$ \\
\hline 121 & 58AA19970225 & Norway/UoB & T. Johannessen & yes & SOMMA & 501 & $\mathrm{OK}$ \\
\hline 122 & 58AA19980308 & Norway/UoB & T. Johannessen & yes & SOMMA & 652 & $\mathrm{OK}$ \\
\hline 125 & 58AA20010527 & Norway/UoB & A. Olsen, A. Omar & yes & SOMMA & 796 & $\mathrm{OK}$ \\
\hline 128 & 58GS20030922 & Norway/UoB & A. Olsen, T. Johannessen & yes & coulometer & 429 & $\mathrm{OK}$ \\
\hline 130 & 58JH19920712 & Iceland/MRI & J. Olafsson & yes & coulometer $^{\mathrm{f}}$ & 224 & $\mathrm{NC}$ \\
\hline 132 & 58JH19930730 & Norway/UoB & T. Johannessen & yes & SOMMA $^{\mathrm{e}}$ & 274 & Flag 3 \\
\hline 134 & 58JH19940525 & Norway/UoB & T. Johannessen & yes & SOMMA & 261 & $\mathrm{OK}$ \\
\hline 135 & 58JH19940723 & Iceland/MRI & J. Olafsson & yes & coulometer $^{\mathrm{e}}$ & 490 & $\mathrm{NC}$ \\
\hline 137 & 58JH19950427 & Norway/UoB & T. Johannessen & yes & SOMMA & 560 & Flag 3 \\
\hline 138 & 58JH19951108 & Norway/UoB & T. Johannessen & yes & SOMMA & 386 & Flag 3 \\
\hline 141 & 58JH19970414 & Sweden/UGOT & L. G. Anderson & yes & coulometer & 725 & $\mathrm{OK}$ \\
\hline 142 & 58JH19980801 & Sweden/UGOT & L. G. Anderson & yes & coulometer & 660 & $\mathrm{OK}$ \\
\hline 176 & 74JC19960720 & Norway/UoB & T. Johannessen & yes & SOMMA & 535 & $\mathrm{OK}$ \\
\hline 179 & 77DN20020420 & Sweden/UGOT & L. G. Anderson & yes & SOMMA & 1386 & $\mathrm{OK}$ \\
\hline 184 & Iceland Sea & Iceland/MRI & J. Olafsson & yes & coulometer & 1232 & $\mathrm{OK}$ \\
\hline
\end{tabular}

${ }^{\text {a }}$ Carina cruisenumber, is cruise identifier in merged file.

${ }^{\mathrm{b}}$ Indicates whether Certified Reference Material (CRM) provided by A. G. Dickson was used on the cruise or not.

${ }^{\mathrm{c}}$ Recommendations from the secondary QC. Flag $3=$ data are questionable and are not included in the final data product; OK = data can be used as they are, $\mathrm{NC}=$ These data are probably $\mathrm{OK}$, but could not be fully evaluated.

d This was the 5th and 6st leg of the 1992 Meteor cruise, only leg 5 samples were used in analyses described in this paper. The method and use of CRMs could not be $100 \%$ confirmed. Most likely a potentiometric technique was used. It is very unlikely that CRMs were measured.

e Analysed ashore.

${ }^{\mathrm{f}}$ First half of samples measured onboard, the rest ashore.

\section{Data provenance}

The Nordic Seas was loosely defined as the region closed by the Fram Strait to the north, Greenland to the west, the Greenland-Scotland Ridge to the south, and Norway, the Barents Sea Opening, and Spitsbergen to the east. Out of the 188 CARINA cruises, 62 are included in the CARINAAMS, and 35 of these considered as Nordic Seas cruises. Five of these are in common with the Atlantic Ocean subset of CARINA (Tanhua et al., 2009a), in order to ensure consistency between the regions. Out of the 35 cruises included in the Nordic Seas CARINA, 25 had $\mathrm{TCO}_{2}$ data. Except for the Iceland Sea time series, the Nordic Seas had only been the subject to sporadic sampling for $\mathrm{TCO}_{2}$ until 1993. That year was the start of a period of quite intense chemical sampling in this region through the ESOP and CARDEEP projects (e.g. Miller et al., 1999). These projects were followed by ESOP2 in 1996, which continued until 1999 (e.g. Chierici et al., 1999), later, between 2001 and 2003, $\mathrm{TCO}_{2}$ sampling was carried out as part of the TRACTOR project (e.g. Olsen et al., 2006). The major part of the $\mathrm{TCO}_{2}$ data from the Nordic Seas in CARINA was obtained through these projects. In addition the collection includes data from the aforementioned repeated visits to the Iceland Sea (approx. $68^{\circ} \mathrm{N}, 13^{\circ} \mathrm{E}$ ) carried out by the Marine Research Institute, Reykjavik, data from the two Nordic WOCE expeditions of 1992 and 1993 and data from the Northeast Water Polynya expeditions of 1992 and 1993 (Yager et al., 1995). The $\mathrm{TCO}_{2}$ data from the Nordic Seas cruise of 1982 onboard CSS Hudson (Chen et al., 1990) and the 1992 Meteor cruise were also subject to secondary QC, but were found to be of too poor quality to be included in the data product, as will be dealt with later.

Table 1 provides an overview of the data that were included in the secondary quality controls described in this paper, and station positions are shown in Fig. 1. Most of the data were obtained using a coulometer, connected either to a SOMMA (single-operator multiparameter metabolic analyzer, Johnson et al., 1993) or similar gas extraction units, in accordance with the standard operating protocols (Dickson et al., 2007). However, data from two of the earlier cruises were obtained using potentiometric techniques. Certified Reference Material (CRM) was used on almost all cruises. 


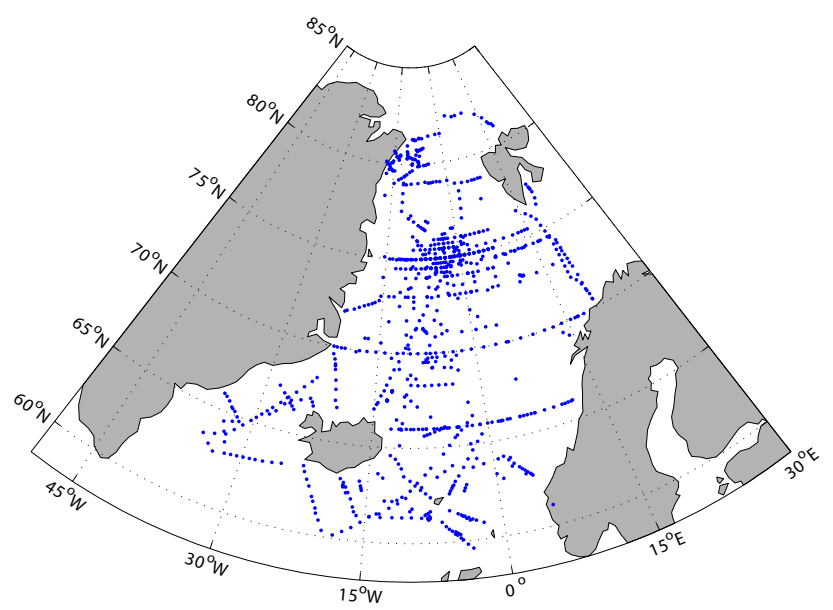

Figure 1. Nordic Seas with $\mathrm{TCO}_{2}$ sampling positions, includes only data retained after secondary quality control.

\section{Quality control}

The secondary QC included an assessment of the precision of the data from each individual cruise as well as a consistency analysis. The consistency analysis was carried out using the crossover and inversion approach (Gouretski and Jancke, 2001; Johnson et al., 2001; Tanhua et al., 2009b), customised as described by Olsen et al. (2009). Another possible approach would be multiparameter linear regressions (MLRs), similar to Wanninkhof et al. (2003), however, at the time of our analyses the consistency of the nutrient data had not been evaluated and since any inconsistencies would propagate into the MLRs, this method was not used.

\subsection{Individual cruise assessments}

The metadata contained little or no information on the precision of the $\mathrm{TO}_{2}$ data obtained at the different cruises, and replicate samples, which would enable us to determine this, were virtually non-existent. However, distribution of chemical properties in the deep Nordic Seas is fairly homogenous (Blindheim and Østerhus, 2005; Fig. 2 of this paper). With this in mind the standard deviation of samples from deeper than $1900 \mathrm{dbar}$ between $65^{\circ}$ and $80^{\circ} \mathrm{N}$ and $10^{\circ} \mathrm{W}$ to $10^{\circ} \mathrm{E}$ on each cruise was estimated in order to obtain an impression of the data spread on each individual cruise. The upper limit of 1900 dbar was selected in order to ensure minimum influence of recently ventilated waters, which reached depths of up to $1600 \mathrm{dbar}$ in the period covered by the CARINA data (Ronski and Budéus, 2005). The standard deviations of the deep data obtained on the different cruises are shown in Table 2. Since the different cruises have been carried out within a month, temporal variations can be excluded at these depths, and the standard deviations should be interpreted with two effects in mind: (1) natural spatial vari-
Table 2. Standard deviation of $\mathrm{TCO}_{2}$ samples collected between 65 and $80^{\circ} \mathrm{N}, 10^{\circ} \mathrm{W}$ and $10^{\circ} \mathrm{E}$, and deeper than $1900 \mathrm{dbar}$.

\begin{tabular}{cccc}
\hline No & EXPOCODE & $\begin{array}{c}\text { std. dev. } \\
\left(\mu \text { mol kg- }^{1}\right)\end{array}$ & $\begin{array}{c}\text { no samples used } \\
\text { for calculation }\end{array}$ \\
\hline 10 & 06MT19920701 & 2.92 & 6 \\
36 & 18HU19820228 & 7.91 & 130 \\
67 & 316N20020530 & 3.10 & 168 \\
79 & 32L919930718 & $\mathrm{NA}^{\mathrm{a}}$ & 0 \\
78 & 32L919920715 & $\mathrm{NA}^{\mathrm{a}}$ & 0 \\
116 & 58AA19940203 & 3.15 & 10 \\
117 & 58AA19940224 & 2.41 & 81 \\
118 & 58AA19940826 & 2.83 & 48 \\
119 & 58AA19950217 & 6.16 & 78 \\
120 & 58AA19961121 & 2.74 & 23 \\
121 & 58AA19970225 & 2.01 & 51 \\
122 & 58A19980308 & 3.51 & 130 \\
125 & 58AA20010527 & 5.06 & 37 \\
128 & 58GS20020922_noEddy & 1.11 & 22 \\
130 & 58JH19920712 & NA & 0 \\
132 & 58JH19930730 & 25.5 & 8 \\
134 & 58JH19940525 & 1.84 & 14 \\
135 & 58JH19940723 & 1.41 & 12 \\
137 & 58JH19950427 & 6.56 & 38 \\
138 & 58JH19951108 & 10.6 & 79 \\
141 & 58JH19970414 & 4.51 & 128 \\
142 & 58JH19980801 & 3.38 & 91 \\
176 & 74JC19960720 & 3.91 & 82 \\
179 & 77DN20020420 & 2.92 & 36 \\
184 & Iceland Sea & NA $^{\mathrm{a}}$ & 0 \\
\hline & & & \\
\hline
\end{tabular}

${ }^{\text {a }}$ Cruise had no samples within area and depths under consideration. b 58GS20030922 had several stations in a submesoscale coherent eddy (Kasajima et al., 2006), the “_noEddy" signifies that these data were removed prior to this analysis.

ability and (2) precision of measurements. As regards the first effect, consider the $316 \mathrm{~N} 20020530$ cruise, which has the largest areal coverage of all cruises with data from almost the full region included in this exercise (Fig. 2). The standard deviation of the deep $\mathrm{TCO}_{2}$ data obtained on this cruise is $3.10 \mu \mathrm{mol} \mathrm{kg}^{-1}$. Since all of the other cruises had smaller areal coverage their standard deviation should be less. This is not the case, most cruises show larger spread, indicating poorer precision. In particular 58JH19930730 with a standard deviation of $25.5 \mu \mathrm{mol} \mathrm{kg}^{-1}$ and $58 \mathrm{JH} 19951108$ with $10.6 \mu \mathrm{mol} \mathrm{kg}^{-1}$. The samples of 58JH19930730 were collected in $50 \mathrm{ml}$ serum bottles, poisoned with $\mathrm{HgCl}_{2}$ and analysed ashore (Miller et al., 1999). This is not in accordance with standard operating procedures (Dickson et al., 2007), and considering the large spread these data appear to be of poor quality and I recommend that they are flagged questionable. Regarding 58JH19951108, Miller et al. (1999) do note that that there were "instrumental difficulties" at this cruise and given this information and the high standard deviation of the deep samples, it is recommended that these data are flagged questionable. 


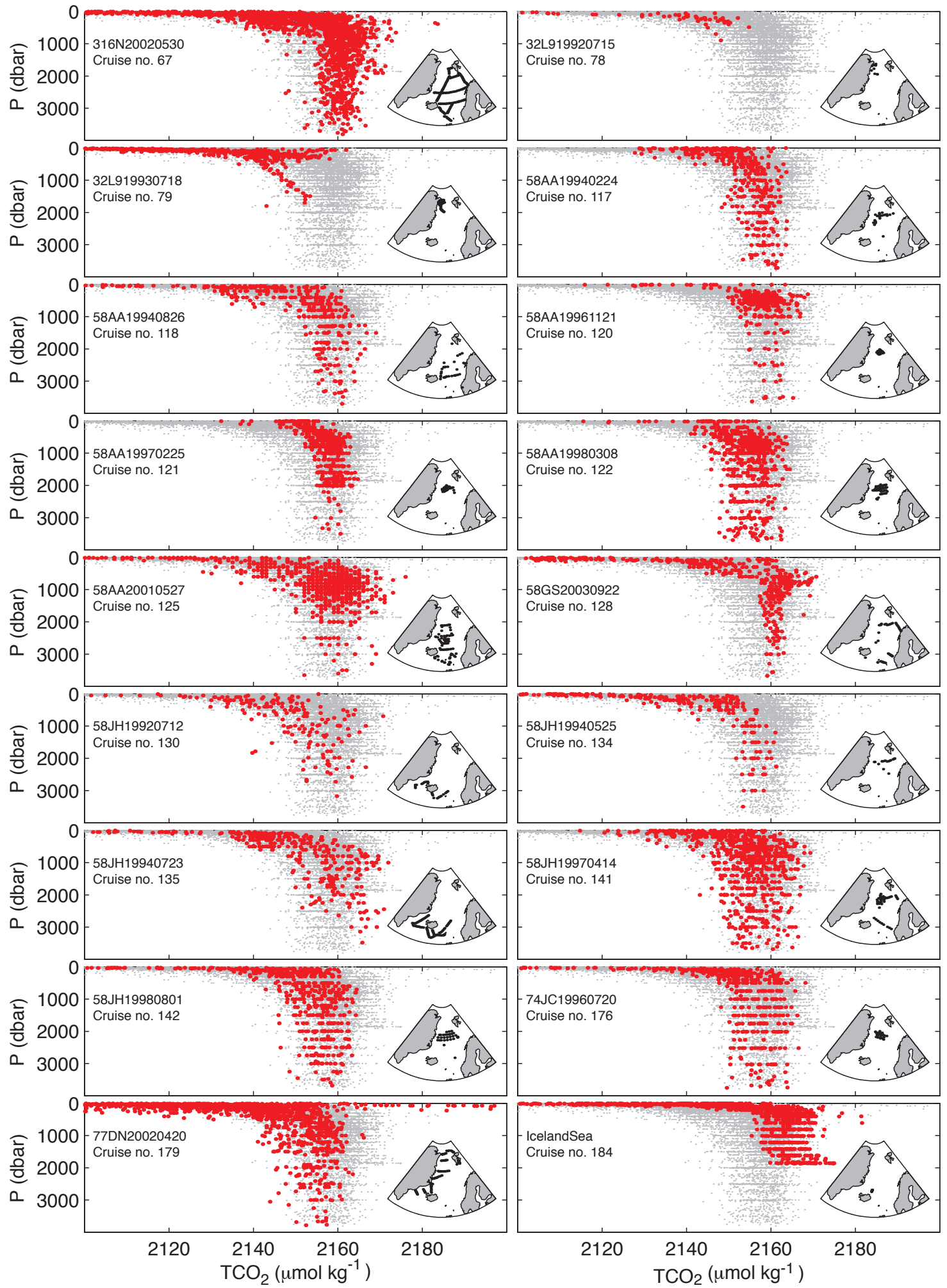

Figure 2. Station positions and $\mathrm{TCO}_{2}$ data of Nordic Seas CARINA cruises after secondary QC. All data shown in grey and specific cruise in red. 
Other than these cruises, the $\mathrm{TCO}_{2}$ data of $18 \mathrm{HU} 19820228$ show high standard deviation. However, this is the oldest cruise included in the synthesis and may have special significance as a reference point when accounting for changes due to anthropogenic carbon input. These data were therefore included in the consistency analyses for further evaluation.

\subsection{Consistency analyses}

The consistency of the Nordic Seas $\mathrm{TCO}_{2}$ data was evaluated through a crossover and inversion analysis (Gouretski and Jancke, 2001; Johnson et al., 2001), carried out using the version of the cnaX routines (Tanhua et al., 2009b) described by Olsen et al. (2009). This approach compares the deep data ( $>1900 \mathrm{~m}$ for the Nordic Seas, cnfr. Sect. 3.1), from two cruises that have stations in vicinity and determines the offset between the data within the crossover of the two cruises, and its standard deviation. Thus each cruise gets a set of offsets compared to the other cruises. This set of offsets are then inverted using the Weighted Least Squares (WLSQ) approach of Johnson et al. (2001) to find the corrections which maximizes the consistency of the data from the different cruises.

For the Nordic Seas data two crossover and inversion analyses were carried out: (1) using only data in CARINA and (2) including the Nordic Seas data from the Transient Tracers in the Ocean - North Atlantic Study (TTO-NAS). The latter analysis was carried out because all evidence suggest that $\mathrm{CO}_{2}$ concentrations in the deep Nordic Seas have increased during the last two decades following the anthropogenic $\mathrm{CO}_{2}$ invasion (Olsen et al., 2006; Skjelvan et al., 2008) and the consistency of the data can not be evaluated without regard for this increase. The TTO-NAS data that were used had been corrected according to Tanhua and Wallace (2005). The data from the two Northeast Water Polynya cruises (32L919920715 and 32L919930718) were not included in the analyses because there were no data from deeper than $1900 \mathrm{dbar}$ and the special sampling area. The $\mathrm{TCO}_{2}$ data from the Iceland Sea time series was not included either, because the bottom depth at the stations is less than $1900 \mathrm{~m}$. The Iceland Sea time series data was, nevertheless, compared with data from other cruises, this is described in Sect. 4.7.

The corrections determined by the WLSQ inversion of the crossover offsets are shown in Fig. 3, the crossover results in themselves can be accessed at the CARINA website (http: //cdiac.ornl.gov/oceans/CARINA/Carina_inv.html). The inclusion of the TTO-NAS data in the analysis had two effects on the results: (1) A correction is suggested for the TTO-NAS data and (2) the suggested correction for 58JH19920712 is reduced. Otherwise the suggested corrections for the different cruises were virtually the same whether the TTO-NAS was included or not (Fig. 3).

Note that the cruises have been sorted with time in Fig. 3, and the inversion suggests that the deep TTO-NAS $\mathrm{TCO}_{2}$ data are nearly $4 \mu \mathrm{mol} \mathrm{kg}^{-1}$ lower than those measured at the

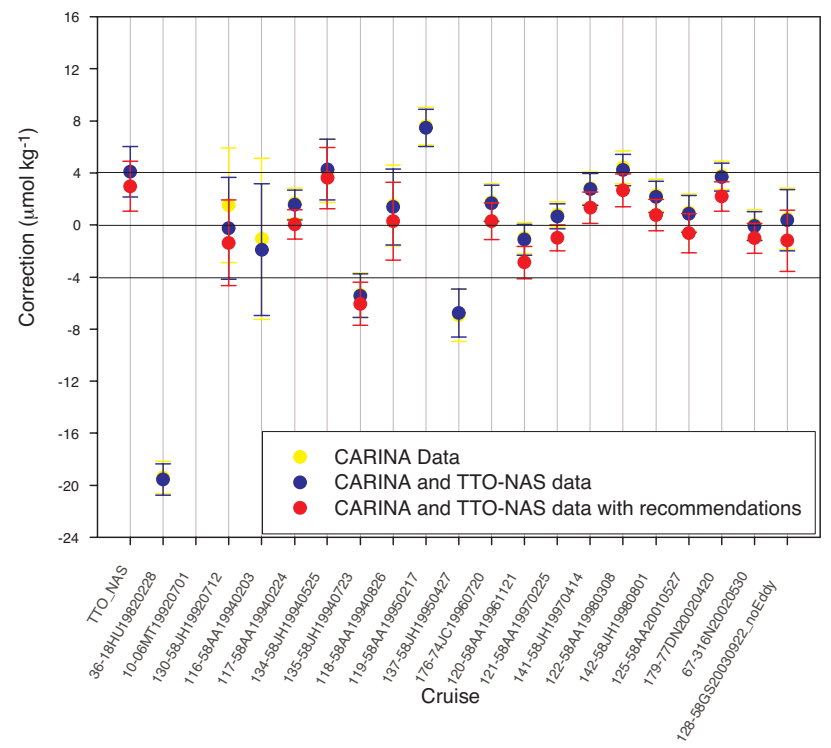

Figure 3. The corrections and their uncertainties (vertical bars) from WLSQ inversion (Johnson et al., 2001) of crossover offsets for (1) the CARINA data, (2) the CARINA and TTO-NAS data, and (3) the CARINA and TTO-NAS data after completed secondary QC. Note that the cruises have been sorted by time in this figure. 58GS20030922 (128) had several stations in a submesoscale coherent eddy (Kasajima et al., 2006), the “_noEddy” signifies that these data were removed prior to this analysis.

316 N20020530 and 58GS20030922 cruises (i.e. they should receive a positive correction of $4 \mu \mathrm{mol} \mathrm{kg}^{-1}$ ). This increase is similar to the deep Greenland Sea anthropogenic $\mathrm{CO}_{2}$ increase determined by Olsen et al. (2006), which may not seem too surprising considering that the same cruises were compared in this study. However, Olsen et al. (2006) did not take any of the data measured in-between into account, whereas the crossover and inversion analyses do. For a meaningful interpretation of the corrections determined by the inversion we have no other option than to assume that this trend is real. Given this, the following features are noteworthy: (1) the $18 \mathrm{HU} 19820228 \mathrm{TCO}_{2}$ data appears to be almost $20 \mu \mathrm{mol} \mathrm{kg}^{-1}$ too high, (2) the 58AA19950217 $\mathrm{TCO}_{2}$ data appears around $5 \mu \mathrm{mol} \mathrm{kg}{ }^{-1}$ lower than the data from the other cruises from the same period, and (3) the three cruises 58AA19940203, 58JH19940723, and 58JH19950427 fall in a "high group" (i.e. they should receive a negative correction). Finally, note that no results were obtained for 06MT19920701 because there were too few samples from deeper than $1900 \mathrm{dbar}$.

\section{Recommendations}

Given the outcome of the crossover and inversion analyses we believe that the following cruises should be considered further: 18HU19820228, 58AA19940203, 58JH19940723, 
58AA19950217, and 58JH19950427. 06MT19920712 is analysed in Sect. 4.6 and the Iceland Sea time series data are analysed in Sect. 4.7.

\section{$4.1 \quad 18 \mathrm{HU} 19820228$}

The $\mathrm{TCO}_{2}$ data of this cruise appear to be almost $20 \mu \mathrm{mol} \mathrm{kg}^{-1}$ higher than expected. They were analysed using potentiometric techniques and not referenced to analysis of CRMs, which were not available at the time these data were acquired. Given the existence of the TTO-NAS data from the previous year one possible solution would be to determine the correction for the $18 \mathrm{HU} 19820228 \mathrm{TCO}_{2}$ data that would bring them into consistency with the TTO-NAS data. Pursuing this approach, an MLR analysis was carried out. Following Olsen et al. (2006) the TTO-NAS $\mathrm{TCO}_{2}$ data obtained north of $62^{\circ} \mathrm{N}$ and deeper than $50 \mathrm{~m}$ were fitted as a function of theta, salinity, nitrate, and silicate:

$\mathrm{TCO}_{2}=67.79 \mathrm{~S}-6.53 \theta-0.096 \mathrm{NO}_{3}+0.65 \mathrm{Si}-222.14$

$r^{2}=0.74, \mathrm{rms}=4.2$

Figure 4 shows deviations of the MLR estimates from the measured $18 \mathrm{HU} 19820228 \mathrm{TCO}_{2}$ data, versus station number. The offsets fall into three groups and decreases with increasing station number. There are also trends in the three sub-groups, in particular in the last. Student-T tests showed that these three groups were different at the $95 \%$ significance level. This cruise is thus not only offset, but the magnitude of this offset varies. No robust adjustment factors can be applied and the recommendation for these data is to flag them questionable.

\subsection{AA19940203}

These data appear too high, around $5 \mu \mathrm{mol} \mathrm{kg}{ }^{-1}$ when compared to data from the same period (Fig. 3). This cruise focused on hydrography and only one chemical oceanographer participated. There are few data, only 84 samples distributed over 16 stations. The alkalinity data from this cruise are of limited quality as well, and it is recommended that the $\mathrm{TCO}_{2}$ data are flagged questionable.

\subsection{JH19940723}

The $\mathrm{TCO}_{2}$ data from cruise appears approximately $9 \mu \mathrm{mol} \mathrm{kg}^{-1}$ too high considering the other cruises from the same period and the expected trend (Fig. 3). It took place, however, mainly in the Nordic Seas-North Atlantic overflow regions, outside of the Greenland Sea. Considering the variability of this region and the limited overlap with the other cruises, evidence does not appear strong enough to recommend an adjustment for these data. The label NC is therefore applied. For consistency, the other cruise with carbon data in this region, 58JH19920712, is labelled NC as well. This is consistent with the decisions made for the other parameters

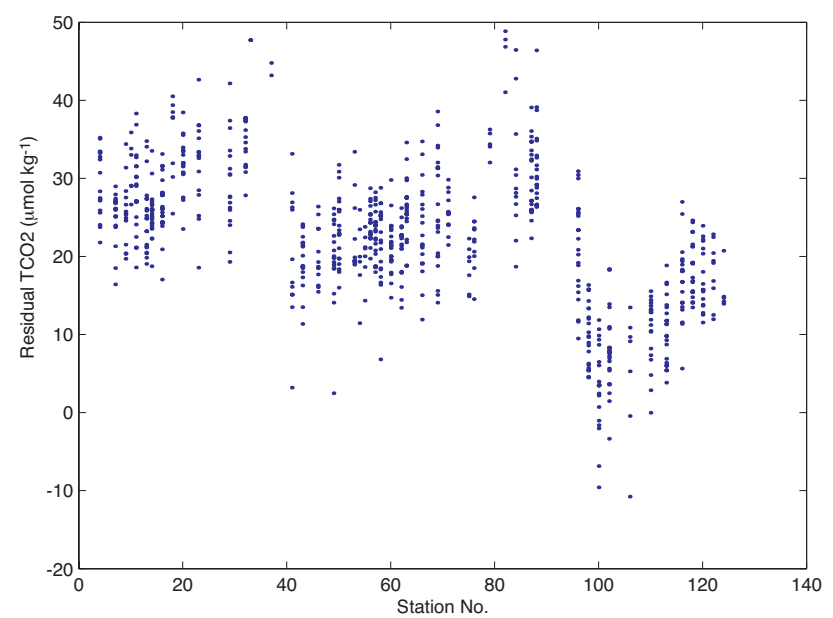

Figure 4. Difference between measured 18HU19820228 $\mathrm{TCO}_{2}$ data and those determined using MLR (Eq. 1), measured - estimated.

measured at these cruises (Olsen et al., 2009; Olafsson and Olsen, 2009; Falck and Olsen, 2009).

\subsection{AA19950217}

Not only do the data appear too low (Fig. 3), but also the standard deviation of deep samples was quite high: $6.16 \mu \mathrm{mol} \mathrm{kg}^{-1}$, twice that of $316 \mathrm{~N} 20020530$ which covered a much larger region (Table 2). The data are thus not only offset, but precision is limited as well. Given this, it is recommended that the $\mathrm{TCO}_{2}$ data from this cruise are flagged questionable.

\subsection{JH19950427}

The data from this cruise appear approximately $9 \mu \mathrm{mol} \mathrm{kg}-1$ too high compared to the expected trend and other data from the same period (Fig. 3). In addition to this, the spread of deep samples was twice that of the deep samples measured during the $316 \mathrm{~N} 20020530$ cruise, which covered a much larger region (Table 2). Given these issues with precision and accuracy, it is recommended that the $\mathrm{TCO}_{2}$ data from this cruise are flagged questionable.

\subsection{MT19920701}

No results were obtained with the crossover and inversion analysis as there were very few data from deeper than $1900 \mathrm{dbar}$ - the minimum sampling depth for data to be considered in the crossovers. Figure 5 shows the $\mathrm{TCO}_{2}$ data from 3 stations of the 06MT19920701 cruise, along with more recent as well as earlier (TTO-NAS) data from the same area, north of Jan Mayen. The 06MT19920701 $\mathrm{TCO}_{2}$ data appears too low, between 5 and $10 \mu \mathrm{mol} \mathrm{kg}{ }^{-1}$. A similar offset was evident in the $\mathrm{TCO}_{2}$ data obtained in the other 


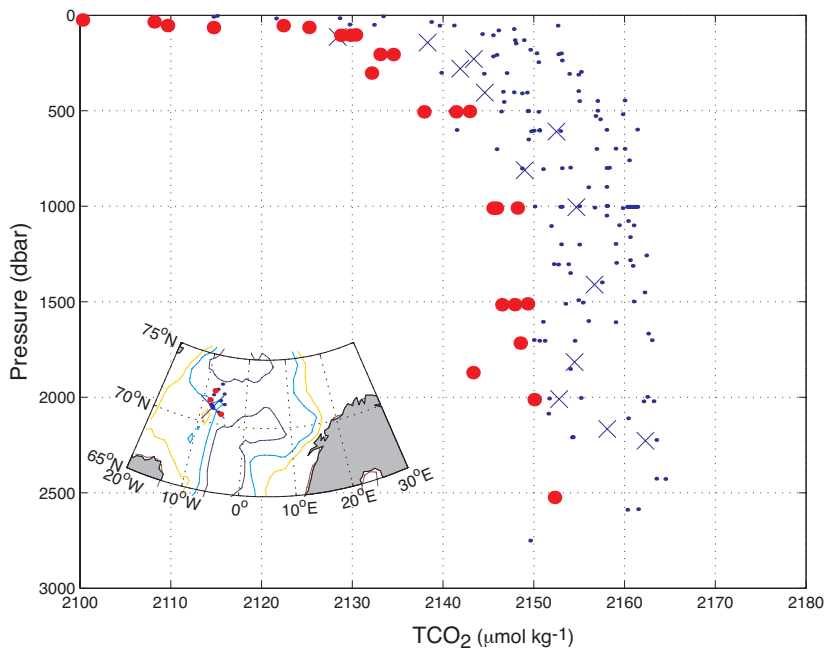

Figure 5. $\mathrm{TCO}_{2}$ data obtained to the north of Jan Mayen at the 06MT19920701 (red dots) cruise, along with data from the TTONAS (Xs) cruise as well as from the other (blue dots), more recent, cruises with $\mathrm{TCO}_{2}$ data in CARINA.

regions covered by this cruise. Gathering information regarding these data was not trivial, as the group that collected them has ceased to exist. The cruise report does not mention whether CRMs were used or not, but given the age we consider it unlikely. It is also not clear whether these samples were measured using potentiometric or coulometric titration, as both types of analytical systems were used on the cruise. However, the latter was carried for testing and we consider it more likely that the reported values are from the potentiometric system. An offset in these data is thus not unlikely. From Fig. 5 it appears to be between 5 and $10 \mu \mathrm{mol} \mathrm{kg}^{-1}$. It cannot be further constrained given the possible anthropogenic change, the scarcity of deep-water samples from this cruise (a total of only 3 samples from below $2000 \mathrm{~m}$ ), and the lack of nutrients data, which prohibits use of MLR. Therefore, rather than possibly introducing errors it is recommended that these data are flagged questionable.

\subsection{Iceland Sea}

These data are collected at two stations northeast of Iceland and given that the bottom depth is less than $1900 \mathrm{~m}$, they were not included in the crossover and inversion analyses, which require sampling depths larger than $1900 \mathrm{dbar}$. Using another approach to evaluate these data, Fig. 6 compares $\mathrm{TCO}_{2}$ and nitrate $\left(\mathrm{NO}_{3}\right)$ data from four different years of the Iceland Sea time series with data from four different cruises which had stations nearby. The nitrate data from 58JH19940826 have been adjusted by a factor of 1.1 as recommended by Olafsson and Olsen (2008). Evaluated from these figures, the Iceland Sea time series data appear reasonable.

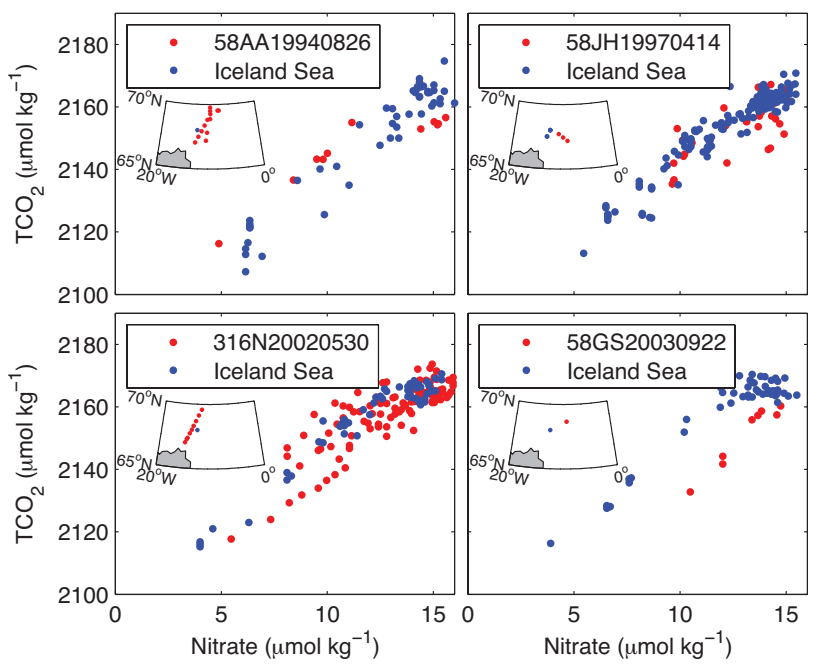

Figure 6. Iceland $\mathrm{Sea} \mathrm{TCO}_{2}$ vs. nitrate, along with data from 4 cruises which had stations in the vicinity.

\section{Consistency test of final Nordic Seas $\mathrm{TCO}_{2}$ data}

In order to evaluate the consistency of the final Nordic Seas $\mathrm{TCO}_{2}$ data, a cnaX crossover and inversion analysis (Tanhua et al., 2009b) was carried out on the set of data after the recommendations had been implemented. The TTO-NAS data were included in this analysis. Corrections determined by the WLSQ inversion of the crossover offsets are shown in Fig. 3. Assuming that the $\mathrm{TCO}_{2}$ concentrations have increased by approximately $4 \mu \mathrm{mol} \mathrm{kg}^{-1}$ over the two decades, and taking into account that 58JH19940723 has been labelled Not Considered, the data appears consistent to at least $4 \mu \mathrm{mol} \mathrm{kg}{ }^{-1}$. The individual cruise tracks and $\mathrm{TCO}_{2}$ profiles of the Nordic Seas data included in the CARINA product are shown in Fig. 2. Note that the recommendations of this paper have been implemented in the merged data product, and the data that were found to be questionable or bad have not been included. They have been retained in the individual cruise files, however, and the data in these have not been adjusted. When the $\mathrm{TCO}_{2}$ data from a whole cruise were found to be questionable as reported here, they were not necessarily flagged as such in the individual cruise files. The flags in these are the ones assigned during the primary QC.

Acknowledgements. This effort would not have been possible without the support of the Norwegian Research Council through ACARB (188167) and the EU through IP CARBOOCEAN (511176). Additional support from the International Ocean Carbon Coordination Project (IOCCP) and the Hanse Institute for Advanced Study (HWK, Delmenhorst, Germany) have been very valuable. I would also like to express my gratitude to R. M. Key at Princeton University, T. Tanhua at Leibniz-Institut für Meereswissenschaften and S. van Heuven at University of Groningen whose extensive efforts 
made the CARINA project possible. Finally I would like to thank the investigators who collected the data at sea, often during adverse conditions, and contributed their data to the CARINA project. The manuscript, which is contribution no. A258 of the Bjerknes Centre for Climate Research, benefitted from reviews by two anonymous referees.

Edited by: V. Gouretski

\section{References}

Blindheim, J. and Østerhus, S.: The Nordic Seas, main oceanographic features, in: The Nordic Seas: an integrated perspective, edited by: Drange, H., Dokken, T., Furevik, T., Gerdes, R., and Berger, W., AGU Geophysical Monograph 158, AGU Washington DC, 2005.

Chen, A., Jones, E. P., and Lin, K.: Wintertime total carbon dioxide measurements in the Norwegian and Greenland Seas, Deep-Sea Res., 37, 1455-1473, 1990.

Chierici, M., Drange, H., Anderson, L. G., and Johannessen, T.: Inorganic carbon fluxes through the boundaries of the Greenland Sea Basin based on in situ observations and water transport estimates, J. Mar. Sys., 22, 295-309 1999.

Dickson, A. G., Sabine, C. L. and Christian, J. R. (Eds.): Guide to best practices for ocean $\mathrm{CO}_{2}$ measurements, PICES Special Publication 3, 191 pp., 2007.

Falck, E. and Olsen, A.: Nordic Seas dissolved oxygen data in CARINA, Earth Syst. Sci. Data Discuss., 2, 537-553, 2009, http://www.earth-syst-sci-data-discuss.net/2/537/2009/.

Gouretski, V. V. and Jancke, K.: Systematic errors as the cause for an apparent deep water property variability: global analysis of the WOCE and historical hydrographic data, Prog. Oceanogr., 48, 337-402, 2001.

Jeansson, E., Olsson, K. A., Tanhua, T., and Bullister, J. L.: Nordic Seas and Arctic Ocean CFC data in CARINA, Earth Syst. Sci. Data Discuss., 2, 493-536, 2009,

http://www.earth-syst-sci-data-discuss.net/2/493/2009/.

Johnson, G. C., Robbins, P. E., and Hufford, G. E.: Systematic adjustments of hydrographic sections for internal consistency, J. Atmos. Ocean. Tech., 18, 1234-1244, 2001.

Johnson, K. M., Wills, K. M., Butler, D. B., Johnson, W. K., and Wong, C. S.: Coulometric total carbon dioxide analysis for marine studies: maximizing the performance on an automated gas extraction system and coulometric detector, Mar. Chem., 44, 167-187, 1993.

Jutterström, S., Anderson, L. G., Bates, N. R., Bellerby, R., Johannessen, T., Jones, E. P., Key, R. M., Lin, X., Olsen, A., and Omar, A. M.: Arctic Ocean data in CARINA, Earth Syst. Sci. Data Discuss., 2, 281-308, 2009,

http://www.earth-syst-sci-data-discuss.net/2/281/2009/.

Kasajima, Y., Olsson, K.A., Johannessen, T., Messias, M.-J., Jeansson, E., Bellerby, R. G. J., and Skjelvan, I.: A submesoscale coherent eddy in the Greenland Sea in 2003, J. Geophys. Res., 111, C07013, doi:10.1029/2005JC003130, 2006.

Key, R. M. Tanhua, T., Olsen, A., Hoppema, M., Jutterström, S., Schirnick, C., van Heuven, S., Lin. X., Wallace, D. W. R., and Mintrop, L.: The CARINA data synthesis project: introduction and overview, Earth Syst. Sci. Data Discuss., in press, 2009.

Miller, L. A., Chierici, M., Johannesen, T., Nojiri, T., Rey, F., and Skjelvan, I.: Seasonal dissolved inorganic carbon variations in the Greenland Sea and implications for atmospheric $\mathrm{CO}_{2}$ exchange, Deep-Sea Res. Pt. II, 46, 1473-1496, 1999.

Olafsson, J. and Olsen, A.: Nordic Seas nutrients data in CARINA, Earth Syst. Sci. Data Discuss., in preparation, 2009.

Olsen, A., Key, R. M., Jeansson, E., Falck, E., Olafsson, J., van Heuven, S., Skjelvan, I., Omar, A. M., Olsson, K. A., Anderson, L. G., Jutterström, S., Rey, F., Johannessen, T., Bellerby, R. G. J., Blindheim, J., Bullister, J. L., Pfeil, B., Lin, X., Kozyr, A., Schirnick, C., Tanhua, T., and Wallace, D. W. R.: Overview of the Nordic Seas CARINA data and salinity measurements, Earth Syst. Sci. Data Discuss., 2, 1-25, 2009,

http://www.earth-syst-sci-data-discuss.net/2/1/2009/.

Olsen, A.: Nordic Seas total alkalinity data in CARINA, Earth Syst. Sci. Data Discuss., 2, 309-330, 2009,

http://www.earth-syst-sci-data-discuss.net/2/309/2009/.

Olsen, A., Omar, A. M., Bellerby, R. G. J., Johannessen, T., Ninnemann, U., Brown, K. R., Olsson, K. A., Olafsson, J., Nondal, G., Kivimäe, C., Kringstad, S., Neill, C., and Olafsdottir, S.: Magnitude and origin of the anthropogenic $\mathrm{CO}_{2}$ increase and ${ }^{13} \mathrm{C}$ Suess effect in the Nordic seas since 1981, Global Biogeochem. Cy., 20, GB3027, doi:10.1029/2005GB002669, 2006.

Skjelvan, I., Falck, E., Rey, F., and Kringstad, S. B.: Inorganic carbon time series at Ocean Weather Station M in the Norwegian Sea, Biogeosciences, 5, 549-560, 2008,

http://www.biogeosciences.net/5/549/2008/.

Ronski, S. and Budéus, G.: Time series of convection in the Greenland Sea, J. Geophys. Res., 110, C04015, doi:10.1029/2004JC002318, 2005.

Tanhua, T., Steinfeldt, R., Key, R. M., Brown, P., Gruber, N., Wanninkhof, R., Perez, F., Körtzinger, A., Velo, A., Schuster, U., van Heuven, S., Bullister, J. L., Stendardo, I., Hoppema, M., Olsen, A., Kozyr, A., Pierrot, D., Schirnick, C., and Wallace, D. W. R.: Atlantic Ocean CARINA data: overview and salinity adjustments, Earth Syst. Sci. Data Discuss., 2, 241-280, 2009a, http://www.earth-syst-sci-data-discuss.net/2/241/2009/.

Tanhua, T., van Heuven, S., Key, R. M., Velo, A., Olsen, A., and Schirnick, C.: Quality control procedures and methods of the CARINA database, Earth Syst. Sci. Data Discuss., 2, 205-240, 2009b, http://www.earth-syst-sci-data-discuss.net/2/205/2009/.

Tanhua, T. and Wallace, D. W. R.: Consistency of TTO-NAS inorganic carbon data with modern measurements, Geophys. Res. Lett., 32, L14618, doi:10.1029/2005GL023248, 2005.

Velo, A., Pérez, F. F., Lin, X., Key, R. M., Tanhua, T., de la Paz, M., van Heuven, S., Jutterström, S., and Ríos, A. F.: CARINA data synthesis project: $\mathrm{pH}$ data scale unification and cruise adjustments, Earth Syst. Sci. Data Discuss., 2, 421-475, 2009, http://www.earth-syst-sci-data-discuss.net/2/421/2009/.

Wanninkhof, R., Peng, T.-H., Huss, B., Sabine, C. L., and Lee, K.: Comparison of inorganic carbon system parameters measured in the Atlantic Ocean from 1990 to 1998 and recommended adjustments, ORNL/CDIAC-140, Carbon Dioxide Information Analysis Center, Oak Ridge National Laboratory, Oak Ridge, Tenn., USA, 43 pp., 2003.

Yager, P. L., Wallace, D. W. R., Johnson, K. M., Smith Jr., W. O., Minnett, P. J., and Deming, J. W.: The Northeast Water Polynya as an atmospheric $\mathrm{CO}_{2}$ sink: A seasonal rectification hypothesis, J. Geophys. Res., 100, 4389-4398, 1995. 